\title{
Correspondence
}

\section{Radionuclide ventriculography in coronary artery disease}

Sir,

The title of the paper by Dr Wieshammer and colleagues- "Limitations of radionuclide ventriculography in the non-invasive diagnosis of coronary artery disease" (1985; 53 :603-10)—deserves comment, lest it be taken to imply that radionuclide ventriculography is of limited use in the management of patients with coronary artery disease. For the title to have reflected all the findings of the study it would have been more reasonable to have omitted the words "radionuclide ventriculography in".

Sensitivity and specificity depend upon the population sampled, and the figures in this paper are not generally accepted experience because of the very low frequency $(25 \%)$ of coronary artery disease in the patients studied. Most British cardiologists would not expect three quarters of coronary arteriograms performed for the investigation of chest pain to be normal, and the point is well made that classic angina is the best indicator of the presence of disease. My own experience at the Middlesex Hospital, gained from a population defined in the same way as that of Wieshammer et al (albeit with a higher frequency of coronary artery disease), is that the figures for sensitivity and specificity of left ventricular ejection fraction are $94 \%$ and $90 \%$ respectively, and as assessed by the standard deviation of the phase histogram the figures are $88 \%$ and $85 \%$ respectively. ${ }^{1}$

The precise figures are not however the point at issue, since no test without perfect specificity is suitable for screening in a population with a low incidence of a disease. More importantly, left ventricular function during stress gives an indication of the functional importance of coronary artery disease, and is therefore of prognostic value in patients with established disease. Irrespective of their coronary artery anatomy, patients without evidence of ischaemia at maximum exercise do well without intervention. $^{2}$

It would be unfortunate if the report of Wies- hammer et al deterred cardiologists unfamiliar with radionuclide ventriculography from making use of the important contribution this technique can make to patient management.

\section{S R Underwood,}

Magnetic Resonance Unit, National Heart and Chest Hospitals, 30 Britten Street, London SW3 6NN.

\section{References}

1 Underwood SR, Walton S, Laming PJ, Ell PJ, Emanuel RW, Swanton RH. Quantitative analysis of stress induced phase changes in the detection of coronary artery disease [Abstract]. Eur 7 Nucl Med 1985; 11: A41.

2 Iskandrian AS, Hakki AH, Kane S, Schenk C. The value of radionuclide ventriculography in risk stratification in patients with known or suspected coronary artery disease [Abstract]. $\mathcal{F}$ Nucl Med 1985; 26: 29.

This letter was shown to the authors, who reply as follows:

Sir,

In reply to Dr Underwood's comments we wish to re-emphasise that our study assessed the role of radionuclide ventriculography in the primary diagnosis of coronary disease only. We have neither stated nor implied that it is of limited value in the management of patients with established coronary disease but rather we share Dr Underwood's opinion about its usefulness in the latter setting.

Each patient who was misdiagnosed by radionuclide ventriculography and referred for coronary bypass surgery had ischaemia at maximum exercise as shown by angina, ST depression, raised left ventricular filling pressure, or a combination of these indicators. The response of left ventricular ejection 
fraction to exercise was reported to be $53 \%-89 \%$ sensitive and $49 \%-100 \%$ specific for coronary disease. ${ }^{1-3}$ Because of these wide ranges "generally accepted experience" is not easy to define. As we pointed out in our paper, the figures for sensitivity and specificity primarily depend upon the research design. We would like to focus on one methodological standard that is hardly ever adhered to in comparable studies. That is the avoidance of a posttest referral bias which occurs if the outcome of the exercise test influences a patient's likelihood of undergoing coronary angiography and thus of being included in the study. Preferential selection of positive test responders will increase the apparent disease frequency and will result in a falsely low specificity and falsely high sensitivity. To our knowledge there is no previous study on radionuclide ventriculography which meets this criterion and reports the number of eligible patients who refused to undergo coronary angiography and therefore had to be excluded. Adherence to this standard accounts for the low frequency of disease in our study group. We are unable to comment on the study design and the results cited by Dr Underwood because the paper he cites has not yet been published.
S Wieshammer,

C Delagardelle,

H A Sigel,

E Henze,

W E Adam,

M Stauch,

Departments of Internal Medicine and Nuclear

Medicine,

University of Ulm Medical Centre,

Steinhoevelstrasse 9,

D-7900 Ulm,

Federal Republic of Germany.

References

1 Borer JS, Kent KM, Bacharach SL, et al. Sensitivity, specificity and predictive accuracy of radionuclide cineangiography during exercise in patients with coronary artery disease. Comparison with exercise electrocardiography. Circulation 1979; 60: 572-80.

2 Osbakken MD, Boucher CA, Okada RD, Bingham JB, Strauss HW, Pohost GM. Spectrum of global left ventricular responses to supine exercise. Limitation in the use of ejection fraction in identifying patients with coronary artery disease. Am $\mathcal{f}$ Cardiol 1983; 51: 28-35.

3 Rozanski A, Diamond GA, Berman D, Forrester JS, Morris D, Swan HJC. The declining specificity of exercise radionuclide ventriculography. $N$ Engl $₹$ Med 1983; 309: 518-22. 